\title{
Comparison and evaluation of two pretreatments of different mechanisms for multi-Fusarium toxins
}

\author{
ZHANG Jia-Ning ${ }^{1, a}$, DING Ke ${ }^{1, b^{*}}$, CHEN Xiang-Ning ${ }^{1, c}$, HAN Tao ${ }^{1, d}$ \\ ${ }^{1}$ Department of Food Science and Engineering, Beijing Laboratory of Food Quality and Safety, \\ Beijing University of Agriculture, Beijing 102206, China \\ as631852@163.com, 'dingk@tom.com, cchenxn1111@vip.sina.com, ${ }^{\mathrm{d}}$ Ilpopopo@hotmail.com
}

Keywords: Immunoaffinity columns, MycoSep®226 multifunction purifying columns, Fusarium toxins, flour , liquid chromatography mass spectrometryzz (LC-MS/MS)

Abstract. A simultaneous determination method for four kinds of Fusarium toxins (zearalenone, deoxynivalenol, T-2 and HT-2 toxins) in flour was established using high performance liquid chromatography-tendem mass spectrometry (LC-MS/MS). Samples were cleaned up with MycoSep®226 multifunction purifying columns and immunoaffinity columns DZT MS-PREP separately. The recovery of the Mycosep ${ }^{\circledR} 226$ multifunction purifying column is $69.42 \% \sim 111.12 \%$, and the relative standard deviation is $1.46 \% \sim 13.24 \%$. The recovery of the immunoaffinity columns DZT MS-PREP is $88.01 \% \sim 107.31 \%$, and the relative standard deviation is $1.09 \% \sim 14.42 \%$. 7 kinds of flour samples were determined, most of the detection results of the immunoaffinity columns DZT MS-PREP were higher than that of the Mycosep ${ }^{\circledR} 226$ multifunction purifying column. The immunoaffinity columns provides an alternative effective and fast tool for simultaneous extraction of the residues of four Fusariumtoxins from real samples.

\section{Introduction}

Fusarium toxins are secondary metabolites produced by Fusarium fungi which is widely distributed in nature ${ }^{[1]}$. They can colonize a broad range of crops and cereals mainly in the field and/or during storage ${ }^{[2,3]}$. Zearalenone (ZEA) and trichothecenes, which include deoxynivalenol (DON), T-2 and HT-2 toxins, are major Fusarim toxins ${ }^{[4]}$ and the most common and dangerous mycotoxins in grain products. ZEA and DON were widely detected in feed, and the associative action of ZEA and DON might destroy the intestinal tract function and break the immunization barrier $^{[5-6]}$, T-2 toxin is the most poisoning toxin in trichothecenes and its major metabolite is HT- $2^{[7-8]}$. Grain products were generally contaminated by the 4 Fusarium toxins above and the detection rate was high. It is essential to have available precise and reliable analytical methods applicable at the regulatory levels for the residue of the four Fusarium toxins.

The main analytical methods for the determination of Fusarium toxins in Grain products are thin layer chromatography (TLC), gas chromatography (GC) ${ }^{[9]}$, gas chromatography-mass spectrometry $(\mathrm{GC}-\mathrm{MS})^{[10]}$, high performance liquid chromatography (HPLC) ${ }^{[11-12]}$ and liquid chromatography mass spectrometry (LC-MS/MS) ${ }^{[13-14]}$. These methods are mainly aimed at the rapid screening, qualitative or quantitative detection of a certain type of toxin or a class of structurally similar toxins $^{[15-16]}$.

Considering the complexity of matrix and the very low concentration of Fusarium toxins in the real samples, these methods could detect trace levels of target analytes when an extensive 
pre-treatment step such as solid phase extraction (SPE) was coupled with ${ }^{[17-21]}$. At present, the multifunction purifying columns and immunoaffinity columns are widely used at home and abroad $^{[22-23]}$. The study on the effect of two kinds of columns on the actual sample is relatively rare, therefore, the comparision of the two different kinds of columns is very important. The aim of this work was to compare the effect of the two different kinds of columns on the enrichment and purification of the four Fusarium toxins in grain products in order to provide the basis for the later experiments. Finally, it was applied to the extraction of an actual flour sample.

\section{Experimental}

\section{Reagents, solutions and apparatus}

Reagents: DON, T-2, HT-2, and ZEA were obtained from Pribolab (Beijing, China). Methanol and acetonitrile (HPLC grade) were obtained from Dima (Buchs, Switzerland). The other reagents were all of analytical grade.

Solutions: (1) $10 \mathrm{mmol} / \mathrm{L}$ ammonium acetate solution; (2) $0.01 \mathrm{~mol} / \mathrm{L}$ phosphate buffered saline

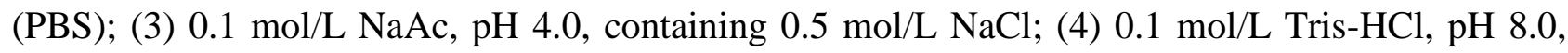
containing $0.5 \mathrm{~mol} / \mathrm{L} \mathrm{NaCl}$; (5) (6) $0.01 \mathrm{~mol} / \mathrm{L} \mathrm{PBS,} \mathrm{pH} \mathrm{7.4;} \mathrm{(7)} \mathrm{0.01} \mathrm{mol/L} \mathrm{PBS,} \mathrm{pH} \mathrm{7.4,} \mathrm{containing}$ $0.01 \% \mathrm{NaN}_{3}$.

Apparatus: Electronic balance (BSA224S, Sartorius, Beijing, China); Ultraviolet visible spectrophotometer (UV-2300, Techcom Com, Shanghai, China); Mycosep ${ }^{\circledR} 226$ multifunction purifying column (Pribolab, Beijing, China); immunoaffinity columns DZT MS-PREP (R-biopharm, Darmstadt, Germany); LC-MS/MS (1200-ESI 6410B, Agilent, Beijing, China).

Flour samples: Select 7 different brands of flour samples from different areas, including 5 kinds of wheat flour and 2 kinds of corn powder. Four kinds of them were purchased from large supermarket of China, the other three kinds were purchased from pedlars' market of China. The type and origin of flour samples were shown as Table 1.

Table 1. The type and origin of flour samples

\begin{tabular}{cllc}
\hline No. & & \multicolumn{1}{c}{ Type } & Producing area \\
\hline 1 & Rich wheat flour & Liaocheng Shandong & Supermarket \\
2 & High gluten wheat flour & Xinxiang Henan & Supermarket \\
3 & Medium cornmeal & Langfang Hebei & Pedlars' market \\
4 & Fine cornmeal & Langfang Hebei & Pedlars' market \\
5 & Strong flour & Tianjin & Pedlars' market \\
6 & Refined wheat flour & Shenyang Liaoning & Supermarket \\
7 & Refined wheat flour & Beijing Daxing & Supermarket \\
\hline
\end{tabular}

\section{LC-MS/MS parameters}

In order to acquire the accurate quantitative results of the four Fusarium toxins extracted from different matrices, the LC-MS/MS method was established. The column was an Agilent ZORBAX Bonus-RP column $(50 \mathrm{~mm} \times 2.1 \mathrm{~mm}, 3.5 \mu \mathrm{m})$ and was kept at $20^{\circ} \mathrm{C}$. A mobile phase gradient programme was used for combining solvent A (Ultra pure water+10 $\mathrm{mM}$ ammonium acetate) and solvent B (acetonitrile) as Table 2, the instrument settings as Table 3. 
Table 2. Gradient elution procedures

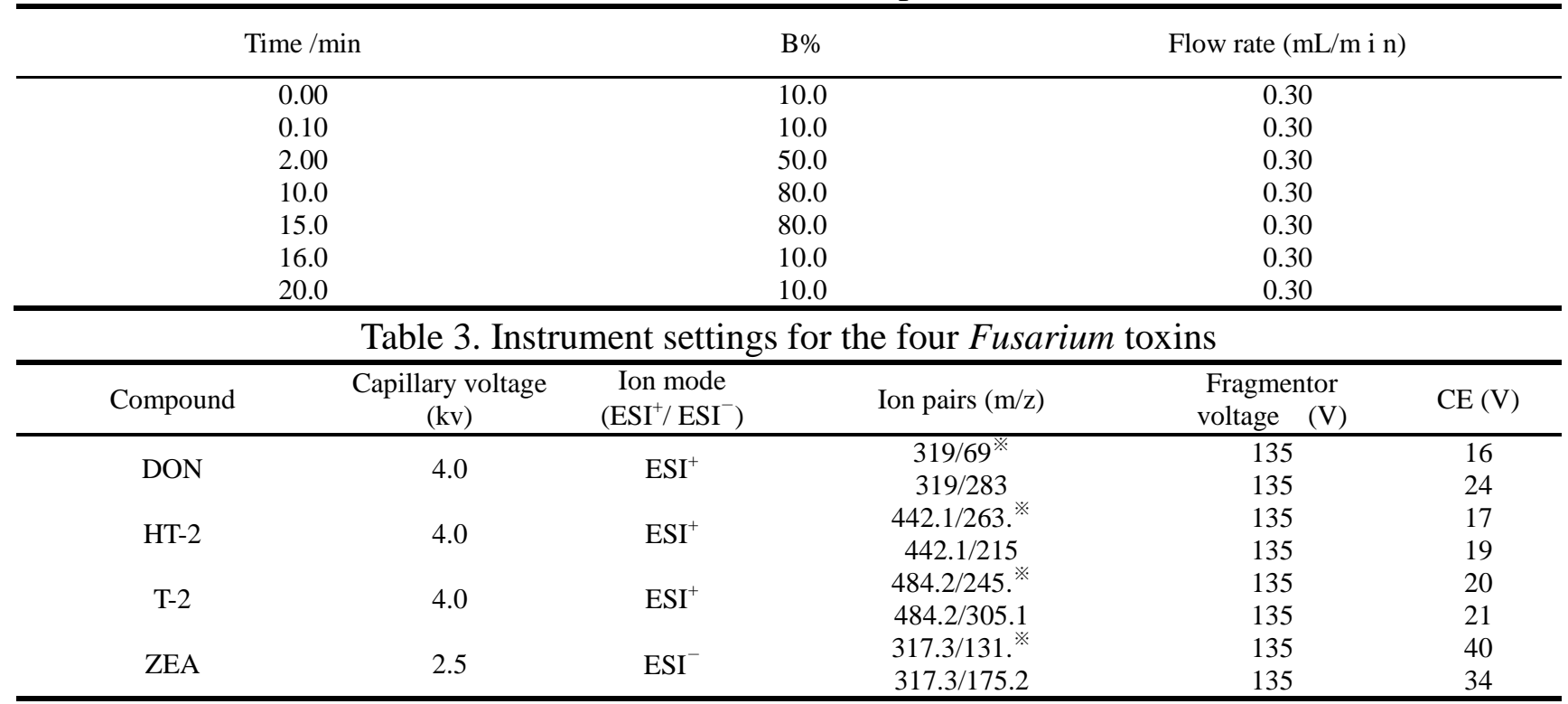

Sample preparation

Mycosep ${ }^{\circledR} 226$ multifunction purifying column

Weigh $25 \mathrm{~g}$ of flour sample into a litre capacity, solvent resistant blender jar, add $100 \mathrm{~mL}$ acetonitrile / water (84: 16, v/v) and blend at high speed for 2 minutes. Filter the sample through the filter paper, or centrifuge at $4000 \mathrm{rmp}$ for 10 minutes. Filter the diluted extract through glass microfiber filter paper. Pass $8 \mathrm{~mL}$ of filtrate through the Mycosep ${ }^{\circledR} 226$ column, take $4 \mathrm{~mL}$ of post column liquid, dried with $\mathrm{N}_{2}$, set the volume to $1 \mathrm{~mL}$ with methanol. Inject $50 \mu \mathrm{L}$ onto the LC-MS/MS system.

\section{Immunoaffinity columns DZT MS-PREP}

Weigh $25 \mathrm{~g}$ of flour sample into a litre capacity, solvent resistant blender jar, add $100 \mathrm{~mL}$ of $70 \%$ methanol (v/v) and blend at high speed for 2 minutes. Filter the sample through the filter paper, or centrifuge at $4000 \mathrm{rmp}$ for 10 minutes. Dilute $2 \mathrm{~mL}$ of filtrate with $48 \mathrm{~mL}$ of phosphate buffered saline (PBS). Filter the diluted extract through glass microfiber filter paper. Pass $20 \mathrm{~mL}$ of filtrate (equivalent to $0.2 \mathrm{~g}$ of sample) through the column at a flow rate of $2 \mathrm{~mL}$ per minute (or the sample can be allowed to pass through the column by gravity if preferred). A slow, steady flow rate is essential for the capture of the toxin by the antibody. Wash the column by passing $20 \mathrm{~mL}$ of water through at a flow rate of approximately $5 \mathrm{~mL}$ per minute. Pass air through the column to remove residual liquid. Elute the toxins from the column at a flow rate of 1 drop per second using $1 \mathrm{~mL}$ of $100 \%$ methanol (v/v) and collect in a $2 \mathrm{~mL}$ amber glass vial. Following elution pass $1 \mathrm{~mL}$ of water through the column and collect in the same vial to give a $2 \mathrm{~mL}$ total volume. Inject $50 \mu \mathrm{L}$ onto the LC-MS/MS system.

Quantitative analysis of the four Fusarium toxins

\section{Calibration curve}

It is recommended to run at least a 3-6 point calibration curve. In constrcting a suitable curve the levels of the calibration standards should bracket or include the range of expected results. To prepare a five point calibration curve, determine the correlation coefficient of the standard curve and the linear range.

\section{Quantitative limit of the method}

Accurately weigh several copies of $25 \mathrm{~g}$ flour samples from each, add standard solution of four 
Fusarium toxins, and gradually reduce the dosage, reduce flour in 4 kinds of mycotoxins concentration. Extract the sample according to the method 2.3, then inject $50 \mu \mathrm{L}$ onto the LC-MS/MS system. It continues until when the detected results of signal-noise ratio is 3:1, and there is no peak appeared in the SIM results. At this time the concentration of four Fusarium toxins in flour are the limits of detection (LOD) of each toxin. The same method to calculate the lower limit of quantification (LOQ) when the detected results of signal-noise ratio is 10:1.

Recovery and precision of the method

Accurately weigh several copies of $25 \mathrm{~g}$ flour samples from each, add different concentrations of standard solution of four Fusarium toxins. Extract the sample according to the method 2.3, then inject $50 \mu \mathrm{L}$ onto the LC-MS/MS system. At the same time, the blank flour sample was detected by the same way. Each sample were made of 3 parallel, repeated 3 times, then calculate the recovery rate and the relative standard deviation (RSD).

Analysis of the effect of different columns applied to the flour samples

Weigh $25 \mathrm{~g}$ of 7 kinds of flour sample and use the two different columns for their pretreatment separately, according to the method 2.3 of extraction, purification and detection. Three parallel should be operated of each sample and repeated three times. Make a comparison of the results of 7 kinds of samples processed by the two different columns.

Repeatability and Stability test of the immunoaffinity columns

The immunoaffinity columns DZT MS-PREP should be tested to use three or more times to verify the repeatability and stability of them. The column should be regenerated after use. It was washed with $0.1 \mathrm{~mol} / \mathrm{L} \mathrm{NaAc}$ containing $0.5 \mathrm{~mol} / \mathrm{L} \mathrm{NaCl}(\mathrm{pH} 4.0)$ and $0.1 \mathrm{~mol} / \mathrm{L}$ Tris-HCl buffer containing $0.5 \mathrm{~mol} / \mathrm{L} \mathrm{NaCl}(\mathrm{pH} \mathrm{8.0)}$ in tunes at least 3 cycles, and the amount of each buffer was fivefold gel volumes. Finally, the column was washed with $0.01 \mathrm{~mol} / \mathrm{L} \mathrm{PBS} \mathrm{(pH} \mathrm{7.4)} \mathrm{and} \mathrm{stored} \mathrm{in}$ the same PBS containing $0.01 \% \mathrm{NaN}_{3}$ for next use. The stability test required continuous measurement of the recovery for the four Fusarium toxins three or more times.

\section{Results and Discussion}

\section{Detection of the four Fusarium toxins by LC-MS/MS}

To establish the LC-MS/MS method for simultaneous detection of the four Fusarium toxins, the optimal analytical condition must be firstly confirmed. Other appropriate conditions for LC-MS/MS analysis were mentioned in Section 2.2. Under this optimal condition, the four Fusarium toxins can be completely separated. As shown on Fig. 1, which was acquired from the mixed standard solution, the retention time for HT-2, T-2, DON and ZEA was $5.336 \mathrm{~min}, 6.105 \mathrm{~min}, 7.673 \mathrm{~min}$ and 7.681 min, respectively. 


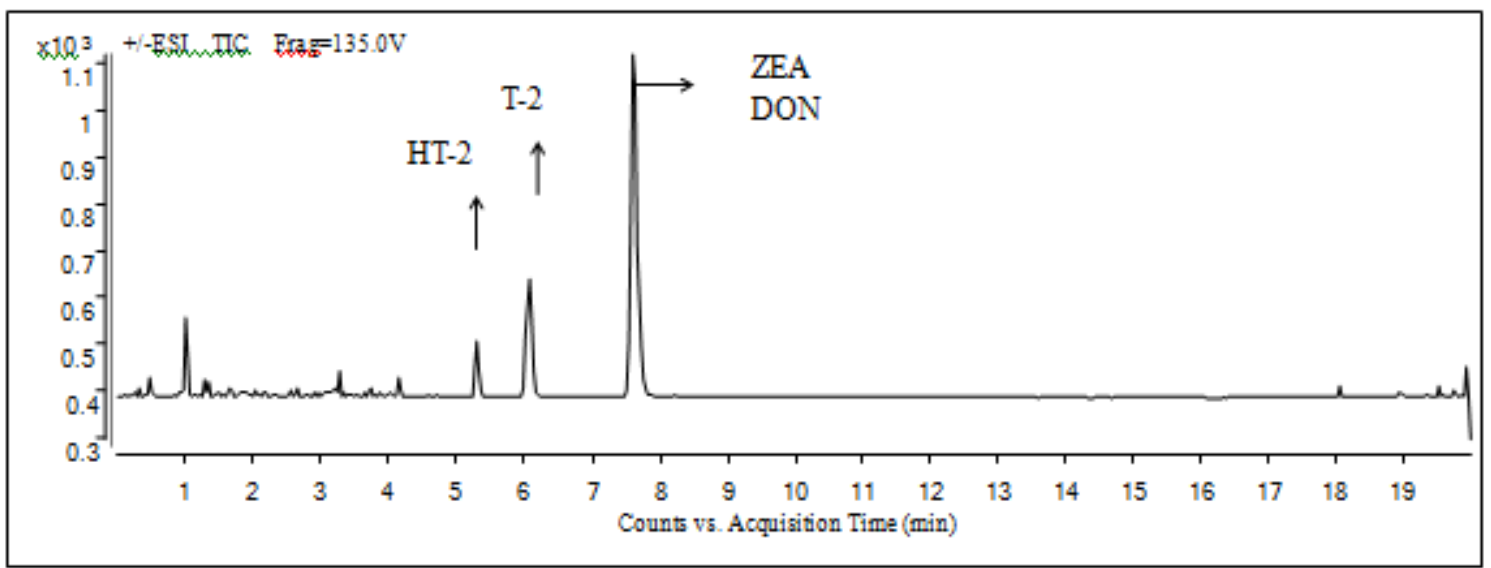

Fig. 1. TIC chromatogram of the four Fusarium toxins standard solutions.

\section{Quantitative analysis of the four Fusarium toxins}

From the standard curves, the liner equation, liner range, correlation coefficient, limit of detection (LOD), limit of quantification (LOQ) were concluded in Table 4. It was seen that the values of LOD of LC-MS/MS for the four Fusarium toxins (DON, HT-2, T-2, ZEA) were 5, 5, 2 and $2 \mu \mathrm{g} / \mathrm{kg}$, respectively.

Table 4. Linear equation, linear ranges, correlation coefficients, detection limit and quantitative lower limit of four Fusarium toxins.

\begin{tabular}{cccccc}
\hline Compound & Linear equation & $\begin{array}{c}\text { Linear range } \\
(\mu \mathrm{g} / \mathrm{kg})\end{array}$ & Correlation coefficient & $\begin{array}{c}\text { LOD } \\
(\mu \mathrm{g} / \mathrm{kg})\end{array}$ & $\begin{array}{c}\text { LOQ } \\
(\mu \mathrm{g} / \mathrm{kg})\end{array}$ \\
\hline DON & $\mathrm{Y}=0.3839 \mathrm{X}-5.9964$ & $5 \sim 100$ & 0.9996 & 5 & 20 \\
HT-2 & $\mathrm{Y}=1.8281 \mathrm{X}-2.9671$ & $5 \sim 100$ & 0.9991 & 5 & 20 \\
T-2 & $\mathrm{Y}=4.7100 \mathrm{X}-8.9354$ & $2 \sim 100$ & 0.9972 & 2 & 5 \\
ZEA & $\mathrm{Y}=20.930 \mathrm{X}-45.793$ & $2 \sim 120$ & 0.9989 & 2 & 5 \\
\hline
\end{tabular}

Recoveries and relative standards deviations of four Fusarium toxins

Weigh $25 \mathrm{~g}$ of one of the flour sample, add standard solution of the four Fusarium toxins gradiently and use the two different columns for their pretreatment separately, according to the method 2.3 of extraction, purification and detection. The results of the Mycosep ${ }^{\circledR} 226$ multifunction purifying column and immunoaffinity columns DZT MS-PREP were showed in Table 5 and Table 6. The recovery of the Mycosep ${ }^{\circledR} 226$ multifunction purifying column is $69.42 \% \sim 111.12 \%$, and the relative standard deviation is $1.46 \% \sim 13.24 \%$. The recovery of the immunoaffinity columns DZT MS-PREP is $88.01 \% \sim 107.31 \%$, and the relative standard deviation is $1.09 \% \sim 14.42 \%$.

The results of the two columns are met the requirements of trace analysis. On the whole, the recovery of the immunoaffinity columns is closer 100\% than that of Mycosep ${ }^{\circledR} 226$ multifunction purifying column as Fig.2. Because the reactions of antigen-antibody are highly specific, the immunoaffinity columns possess great sensitivity and selectivity. 
Table 5. Recoveries and RSDs of Fusarium toxins using Mycosep ${ }^{\circledR} 226$ purifying column .

\begin{tabular}{cccc}
\hline Compound & Additive amount $/ \mu \mathrm{g} / \mathrm{kg}$ & Recoveries $/ \%$ & 4.24 \\
\hline \multirow{2}{*}{ DON } & 25 & 85.12 & 9.95 \\
& 50 & 75.29 & 3.09 \\
& 100 & 84.09 & 1.46 \\
HT-2 & 25 & 84.09 & 5.69 \\
& 50 & 80.02 & 2.78 \\
T-2 & 100 & 76.99 & 6.35 \\
& 10 & 82.65 & 3.03 \\
& 25 & 73.38 & 4.23 \\
ZEA & 50 & 73.19 & 13.24 \\
& 10 & 86.54 & 2.52 \\
\hline
\end{tabular}

\begin{tabular}{cccc}
\hline \multicolumn{3}{c}{ Table 6. Recoveries and RSDs of Fusarium toxins using immunoaffinity columns DZT MS-PREP. } \\
\hline Compound & Additive amount $/ \mu \mathrm{g} / \mathrm{kg}$ & Recoveries $/ \%$ & RSD/\% \\
\hline \multirow{3}{*}{ DON } & 25 & 107.31 & 7.09 \\
& 50 & 100.77 & 8.44 \\
& 100 & 93.34 & 11.20 \\
& 25 & 92.13 & 1.09 \\
HT-2 & 50 & 91.71 & 5.21 \\
& 100 & 88.01 & 4.36 \\
& 10 & 101.00 & 8.56 \\
T-2 & 25 & 104.45 & 14.42 \\
& 50 & 97.66 & 1.95 \\
& 10 & 98.57 & 5.77 \\
ZEA & 25 & 93.11 & 13.83 \\
& 50 & 88.02 & 9.91 \\
\hline
\end{tabular}

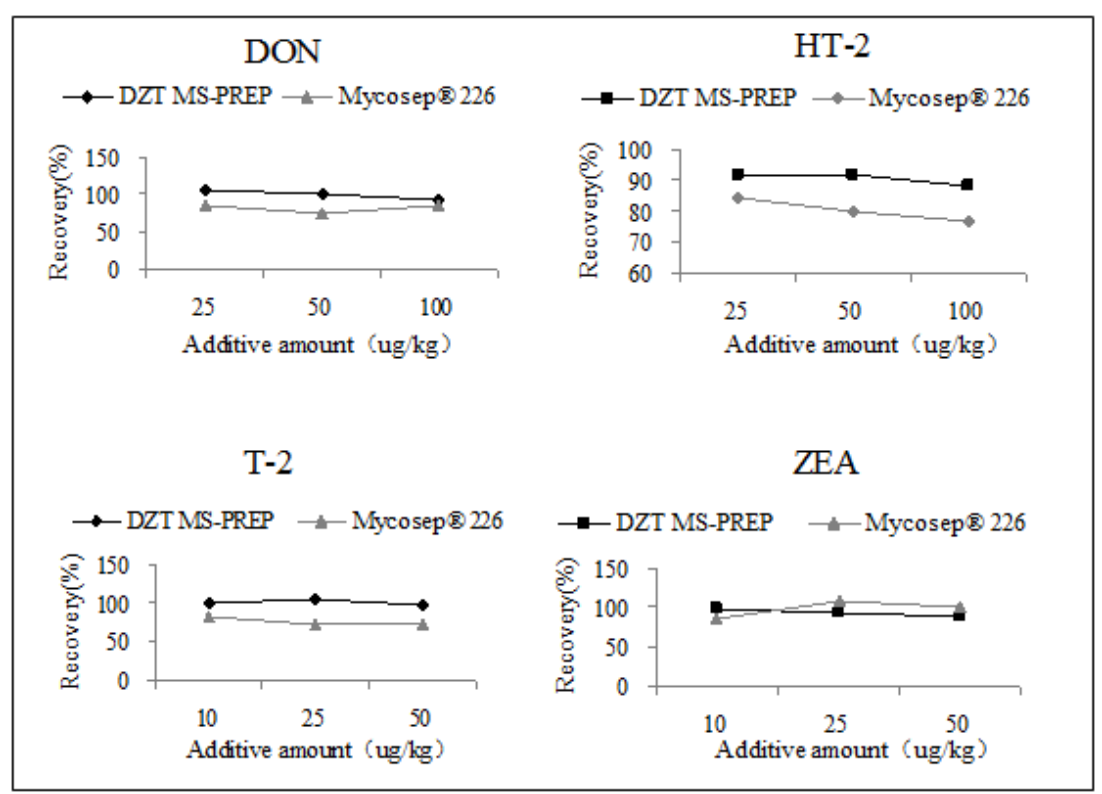

Fig. 2. Comparison of recovery of two different kinds of columns 
Analysis of the effect of different columns applied to the flour samples

Weigh $25 \mathrm{~g}$ of 7 kinds of the flour sample, and use the two different columns for their pretreatment separately, according to the method 2.3 of extraction, purification and detection. The result of the Mycosep ${ }^{\circledR} 226$ multifunction purifying column showed that the detection rate of DON, HT-2, T-2 were $100 \%$ as Table 7, ZEA was detected only in No 1,3,4,5 flour samples, and the average content of the four Fusarium toxins were all the highest of No 4 flour sample. The result of the immunoaffinity columns DZT MS-PREP showed that the detection rate of DON, HT-2, T-2, ZEA were $100 \%$ as Table 8 , most of the detection results were higher than that of the Mycosep ${ }^{\circledR}$ 226 multifunction purifying column. Considering the complexity of matrix and the very low concentration of the four Fusarium toxins in real samples analysis, the immunoaffinity columns DZT MS-PREP was the better choice. What's more, the organic solvent used in the purification with the immunoaffinity columns was less than that of with the Mycosep ${ }^{\circledR} 226$ multifunction purifying column.

In the national standards GB 2761-2005 " Limit of Mycotoxins in food ", there are limits of DON and ZEA in wheat, corn and barley, it shows that DON $\leq 1000 \mu \mathrm{g} / \mathrm{kg}, \mathrm{ZEA} \leq 60 \mu \mathrm{g} / \mathrm{kg}$. However, the results in Table 7 and Table 8 reflect that the content of No 3,4 samples beyond the limits of national standards. So far, the specific standards of HT-2 and T-2 have not been published in China. Based on the application of the actual testing, the limited standards of HT-2, T-2 need to be improved.

\section{The repeatability of the immunoaffinity columns DZT MS-PREP}

The Mycosep ${ }^{\circledR} 226$ multifunction purifying column can not be reused, however, the immunoaffinity columns are reproducible. The results were shown in Fig. 3 after the immunoaffinity columns DZT MS-PREP were used for three times. Compared the recovery after use. It can be concluded that after each use, the recovery of each toxin were reduced, but the reduction was not significant. The immunoaffinity columns can be used repeatedly, which greatly saves the cost and improves its efficiency.

Table 7. The results of 7 kinds of flour samples using Mycosep® 226 purifying column .

\begin{tabular}{|c|c|c|c|c|c|c|c|c|}
\hline \multirow[b]{2}{*}{ Number } & \multicolumn{2}{|c|}{ DON } & \multicolumn{2}{|c|}{ HT-2 } & \multicolumn{2}{|c|}{ T-2 } & \multicolumn{2}{|c|}{ ZEA } \\
\hline & $\begin{array}{l}\text { Average } \\
\text { content } \\
(\mu \mathrm{g} / \mathrm{kg})\end{array}$ & $\begin{array}{l}\text { RSD } \\
(\%)\end{array}$ & $\begin{array}{c}\text { Average } \\
\text { content } \\
(\mu \mathrm{g} / \mathrm{kg})\end{array}$ & $\begin{array}{l}\text { RSD } \\
(\%)\end{array}$ & $\begin{array}{l}\text { Average } \\
\text { content } \\
(\mu \mathrm{g} / \mathrm{kg})\end{array}$ & $\begin{array}{l}\text { RSD } \\
(\%)\end{array}$ & $\begin{array}{c}\text { Average } \\
\text { content } \\
(\mu \mathrm{g} / \mathrm{kg})\end{array}$ & $\begin{array}{l}\text { RSD } \\
(\%)\end{array}$ \\
\hline 1 & 30.18 & 5.47 & 31.45 & 15.22 & 11.70 & 6.02 & 10.48 & 7.26 \\
\hline 2 & 27.73 & 4.68 & 29.04 & 9.08 & 12.51 & 13.758 & - & - \\
\hline 3 & 115.32 & 2.51 & 29.01 & 8.97 & 11.81 & 4.81 & 68.84 & 4.30 \\
\hline 4 & 245.14 & 4.29 & 34.44 & 13.09 & 15.41 & 6.09 & 144.162 & 9.61 \\
\hline 5 & 30.00 & 4.82 & 32.85 & 9.08 & 13.93 & 16.20 & 11.42 & 7.63 \\
\hline 6 & 17.93 & 2.18 & 21.42 & 5.50 & 12.69 & 5.04 & - & - \\
\hline 7 & 29.00 & 5.58 & 30.31 & 6.26 & 14.69 & 2.92 & - & - \\
\hline
\end{tabular}

Table 8. The results of 7 kinds of flour samples using immunoaffinity columns DZT MS-PREP.

\begin{tabular}{|c|c|c|c|c|c|c|c|c|}
\hline \multirow[b]{2}{*}{ Number } & \multicolumn{2}{|c|}{$\mathrm{DON}$} & \multicolumn{2}{|c|}{ HT- 2} & \multicolumn{2}{|c|}{ T-2 } & \multicolumn{2}{|c|}{ ZEA } \\
\hline & $\begin{array}{l}\text { Average } \\
\text { content } \\
(\mu \mathrm{g} / \mathrm{kg})\end{array}$ & $\begin{array}{l}\text { RSD } \\
(\%)\end{array}$ & $\begin{array}{l}\text { Average } \\
\text { content } \\
(\mu \mathrm{g} / \mathrm{kg})\end{array}$ & $\begin{array}{l}\text { RSD } \\
(\%)\end{array}$ & $\begin{array}{c}\text { Average } \\
\text { content } \\
(\mu \mathrm{g} / \mathrm{kg})\end{array}$ & $\begin{array}{l}\text { RSD } \\
(\%)\end{array}$ & $\begin{array}{l}\text { Average } \\
\text { content } \\
(\mu \mathrm{g} / \mathrm{kg})\end{array}$ & $\begin{array}{l}\text { RSD } \\
(\%)\end{array}$ \\
\hline 1 & 57.45 & 5.11 & 16.80 & 3.41 & 13.84 & 2.88 & 16.52 & 3.55 \\
\hline 2 & 61.22 & 0.02 & 24.22 & 4.61 & 18.90 & 5.06 & 16.36 & 8.26 \\
\hline 3 & 129.13 & 9.00 & 34.85 & 2.56 & 19.72 & 6.96 & 61.36 & 0.81 \\
\hline 4 & 238.23 & 4.53 & 26.43 & 2.92 & 13.53 & 13.44 & 128.06 & 0.22 \\
\hline 5 & 66.29 & 1.62 & 30.16 & 0.49 & 19.23 & 6.69 & 16.83 & 0.67 \\
\hline 6 & 67.13 & 1.46 & 28.64 & 5.41 & 19.44 & 5.64 & 15.80 & 0.09 \\
\hline 7 & 71.25 & 3.29 & 21.35 & 7.12 & 14.36 & 13.25 & 15.92 & 0.09 \\
\hline
\end{tabular}




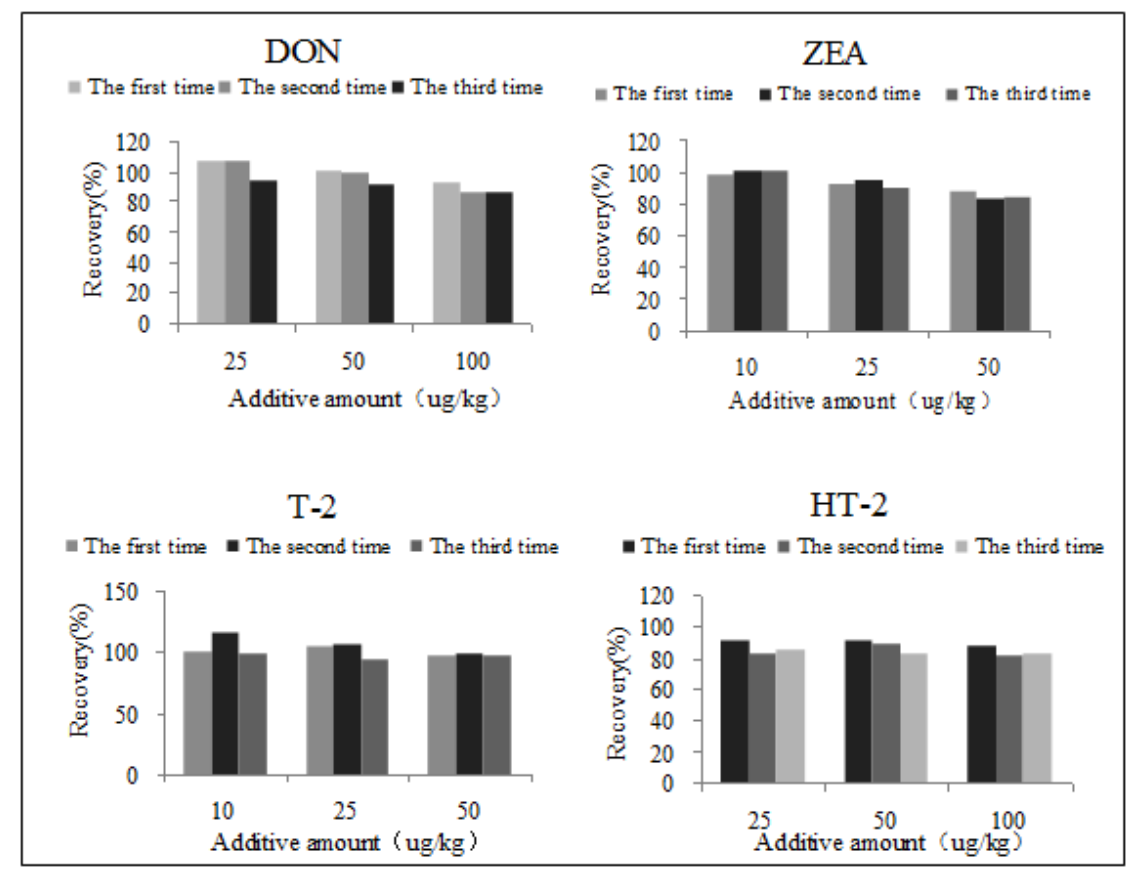

Fig. 3. The recovery after used the immunoaffinity columns DZT MS-PREP for different times.

\section{Conclusion}

In this study, Mycosep ${ }^{\circledR} 226$ multifunction purifying columns and immunoaffinity columns DZT MS-PREP for simultaneously selective purification of Fusarium toxins (zearalenone, deoxynivalenol, and T-2 and HT-2 toxins) residues from grain products were compared. Applied to actual flour samples, the recovery of the Mycosep ${ }^{\circledR} 226$ multifunction purifying column is $69.42 \% \sim 111.12 \%$, and the relative standard deviation is $1.46 \% \sim 13.24 \%$. The recovery of the immunoaffinity columns DZT MS-PREP is $88.01 \% \sim 107.31 \%$, and the relative standard deviation is $1.09 \% \sim 14.42 \%$.

7 kinds of flour samples were determined. The result of the Mycosep ${ }^{\circledR} 226$ multifunction purifying column showed that the detection rate of DON, HT-2, T-2 were 100\%, ZEA was detected only in No 1,3,4,5 flour samples. The result of the immunoaffinity columns DZT MS-PREP showed that the detection rate of DON, HT-2, T-2, ZEA were $100 \%$, most of the detection results were higher than that of the Mycosep ${ }^{\circledR} 226$ multifunction purifying column.

In a word, the immunoaffinity columns have the advantages of high sensitivity, low matrix interference and low cost, and they are better than the Mycosep ${ }^{\circledR} 226$ multifunction purifying columns applied to the purification of the four Fusarium toxins (zearalenone, deoxynivalenol, T-2 and HT-2 toxins) residues in real grain products analysis. The immunoaffinity columns provide an alternative effective and fast tool for simultaneous extraction of the residues of four Fusarium toxins from real samples.

\section{Acknowledgements}

The authors would like to express their gratitude to the Importation and Development of High-Caliber Talents Project of Beijing Municipal Institutions (CIT\&TCD20154045), the Beijing Natural Science Fund (14L00184) and The Degree and Graduate Education Reform and Development Project of BUA in 2015 (2015YJS034) for the financial support of this study. 


\section{References}

[1] J.W. Bennet, M. Klich: Clin.Microbiol Vol. 16 (2003), p. 497.

[2] A. Visconti, V. Lattanzio, T. Maria, et al: J. Chromatogr. A Vol. 1075 (2005), p. 151.

[3] C. Booth: The genus Fusarium, Commonwealth Agricultural, 1971.

[4] P.W. Christopher, Y.Y. Gong: Carcinogenesis Vol. 31 (2010), p. 71.

[5] B.A. Rotter, D.B. Prelusky, J.J. Pestka: J Toxicol Environ Health Vol. 48 (1996), p. 1.

[6] A. Chanemougasoundharam, M.D. Fiona: Toxicol. Lett. Vol. 217 (2010), p. 149.

[7] A. Visconti, V. Lattanzio, T. Maria, et al: J. Chromatogr. A Vol. 1075 (2005), p. 151.

[8] P.W. Christopher, Y.Y. Gong: Carcinogenesis Vol. 31 (2010), p. 71.

[9] F. Kotal, K. Holadova, J. Hajšlová, et al: J. Chromatogr. A Vol. 830 (1999), p. 219.

[10] Z. Eke, A. Kende, K. Torkos: Microchem. J. Vol. 78 (2004), p. 211.

[11] F. Soleimany, S. Jinap, A. Rahmani, et al: Food Addit. Contam. Vol. 28 (2011), p. 494.

[12] C.Y. Choi, H. Nakajima-Adachi, S. Kaminogawa, et al: Toxicol. Appl. Pharmacol. Vol. 165 (2000), p. 94.

[13] U. Brezina, I. Rempe, S. Kersten, et al: Arch. Anim Nutr Vol. 68 (2014), p. 425.

[14] C. Dall'Asta, S. Sforza, G. Galaverna, et al: J. Chromatogr. A Vol. 1054 (2004), p. 389.

[15] A. Elisabetta, M. Linda, P. Michelangelo, et al: Food Addit. Contam Vol. 30 (2013), p. 345.

[16] Q. Wang, H. Zhao, C.X. Xi, et al: Food Addit. Contam Vol. 31 (2014), p. 1177.

[17] B. Romagnoli, M. Ferrari, C. Bergamini: J. Mass spectrom. Vol. 45 (2010), p. 1075.

[18] Z. Radová, K. Holadová, J. Hajšlová: J. Chromatogr. A Vol. 829 (1998), p. 259.

[19] T. Tanaka, A. Yoneda, S. Inoue, et al: J. Chromatogr. A Vol. 882 (2000), p. 23.

[20] M. Vaclavikova, S. MacMahon, K. Zhang, et al: Talanta Vol. 117 (2013), p. 345.

[21] V.M.T. Lattanzio, M. Solfrizzo, S. Powers, et al: Rapid Commun. Mass Spectrom. Vol. 21 (2007), p. 3253.

[22] M. Liyun, C. Biyun, Y. Hong, et al: J. Chromatogr. B Vol. 945-946 (2014), p. 178.

[23] E. Razzazi-Fazeli, J. Böhm, K. Jarukamjorn, et al: J. Chromatogr. B Vol. 796 (2003), p. 21. 